\title{
Headlines
}

\section{Worldwide Pay and Benefits}

\section{Compiled and written by Towers Perrin in March 2002}

\section{HeadlinesOnline}

To access the current issue or search an archive of back issues of Headlines, visit Towers Perrin online at www.towersperrin.com

\section{International}

\section{Downturn in global markets poses a challenge for pension plan sponsors}

Last year's downturn in capital markets had a major impact on the financial performance of pension plans around the world, reducing typical plan funded levels by 10 per cent to 15 per cent, according to a periodic Towers Perrin review of defined benefit (DB) pension plans in selected countries.

This is the second straight year of disappointing results for pension plans in the countries studied. When combined with year 2000 results, benchmark plans in the USA, UK, Japan and the Euro-zone saw drops in funded levels of approximately 25 per cent. Canada and Australia fared slightly better, with two-year losses of around 15 per cent. The results in 2001 are a reflection of the combined impact of poor investment results and increasing liabilities. In most of the countries studied, equity returns were negative for the year, and declining interest rates contributed to higher liabilities.

Given the 2000 and 2001 results, multinationals should consider a number of important steps to make sure they are managing their worldwide pension plans by following sound financial practices. Specifically, they should:

- Review the funded status of individual plans. Due to poor investment returns, plans may be in a deficit position that brings balance sheet implications in the consolidated financial reporting process. This is particularly true of plans that may have missed out on the 1990s bull market, for example in Japan or, to a lesser extent, in the Euro zone.

- Review local funding or contribution requirements. The capital market declines over the past two years may impact local funding or contribution requirements. This can be especially relevant in countries where local legislation mandates minimum funding levels for pension plans, such as the USA and the UK.

- Review all assumptions. Liability and expense calculations depend on a number of assumptions other than the commonly quoted ones such as the discount rate. Plan sponsors may want to revisit the broader set of actuarial assumptions.

- Review or update asset liability management (ALM) studies. Significant events have occurred in the last two years that can affect pension plan risk levels. On the liability side, employee demographics may have changed due to layoffs or hiring freezes. On the asset side, poor investment returns and 


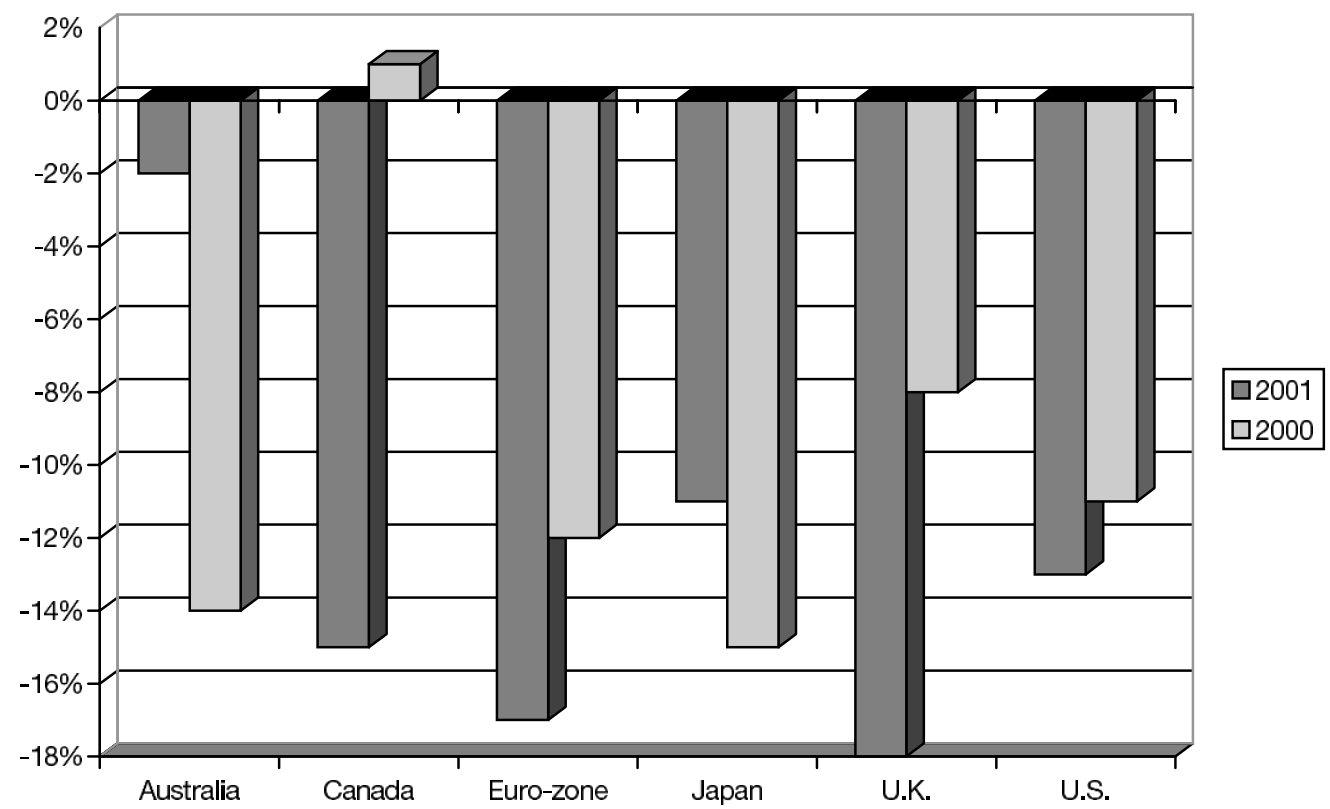

Figure 1: Percentage change in funded status of benchmark plans in selected countries

potentially higher benefit payments (particularly for plans that offer lump sums) may have lowered the level of plan assets, especially in the case of plans on contribution holidays.

\section{Results by country}

As shown in Figure 1, all the regions surveyed recorded decreases in funded status for their benchmark plans in the last two years, except for a 1 per cent gain in Canada in 2000. The benchmark portfolio returns in each country are based on a typical diversified mix of domestic and international stocks as well as selected fixed-income securities.

Liability calculations in each country are based on typical defined benefit plan designs covering a relatively mature population of employees and retirees. In practice, the actual impact will depend on a number of company and/or country-specific factors.

For further information please contact Massimo Borghello (borghem@towers.com), New York +1-212-309-3528, or Bob Holdom (holdomr@towers.com), New York +1-212-309-3698.

\section{Global companies are missing opportunities to trim benefit costs}

Most multinational companies are failing to take full advantage of key financial management techniques that can help reduce the cost of their worldwide benefit plans, according to a recent Towers Perrin study. The study, 'Worldwide Benefits Management Report', is based on a survey of 157 global organisations, including 25 per cent of Europe's top 100 companies. Over 80 per cent of respondents ranked controlling costs and preventing financial surprises as leading priorities for the future in managing their worldwide benefit policies. However, despite an increasing desire to cut costs, the survey results showed that most companies are missing 
opportunities to manage the costs associated with employee benefit plans.

For example, while 41 per cent of respondents indicated that they had implemented multinational pooling of insurance risk on a global basis, another 48 per cent said there was no consolidation of employee insurance plans. As shown in Figure 2, other areas of potential cost savings were cited even less frequently.

\section{Alignment with HR and business goals}

While half of the companies surveyed cited cost control as a core reason for establishing a global benefit strategy, many companies also indicated that pursuing a global benefit strategy would help their organisations achieve other key HR and business objectives, namely to:

- achieve consistency in reward strategies and other HR policies

- support recruitment and retention

— improve global competitiveness

- improve local competitiveness.

Clearly, multinationals in many parts of the world are showing increased interest in a worldwide approach to managing their employee benefits and, as the costs of retirement and other benefit programmes rise, they are beginning to focus on the financial implications of these policies.

However, employers can often do more from an organisational standpoint alone to bring more of a financial focus to their benefit programmes. Nearly two-thirds (64 per cent), for example, said there was no group finance involvement in determining benefit strategy, and only about a third cited the combined involvement of their HR and finance groups in benefit strategy discussions.

Perhaps it is not surprising, then, that while more than half of survey respondents said they believed the elements driving their benefit strategy related to the company's key business objectives, only 5 per cent felt they were successful in aligning benefits with their business objectives.

\section{Communication may be lacking}

Other Towers Perrin research shows that benefit plans will not support a company's business goals and objectives if employees do not understand the true value of their benefits. However, in this case, almost half of all companies felt that communication of benefit details was a local rather than a global issue. Only 2 per cent of respondents felt they were successful in communicating benefit messages on a global basis, and over 50 per cent did not measure employees' perception of the benefits provided by employers.

For further information please contact Nigel Bateman (bateman@towers.com), London, +44-(0)20-8895-3524.

\section{Argentina}

\section{Economic crisis brings far-reaching choices in HR policies}

Argentina's economic crisis is having far-reaching consequences for employers, forcing them to consider a variety of adjustments to employees' pay and benefit packages as they struggle to stay in business.

While there are predictions that the economy will begin to recover by the end of 2002, some important trends and changes in HR practices are under way at many companies, including multinationals operating in the country:

- Most companies are planning to grant base salary increases aligned to market 


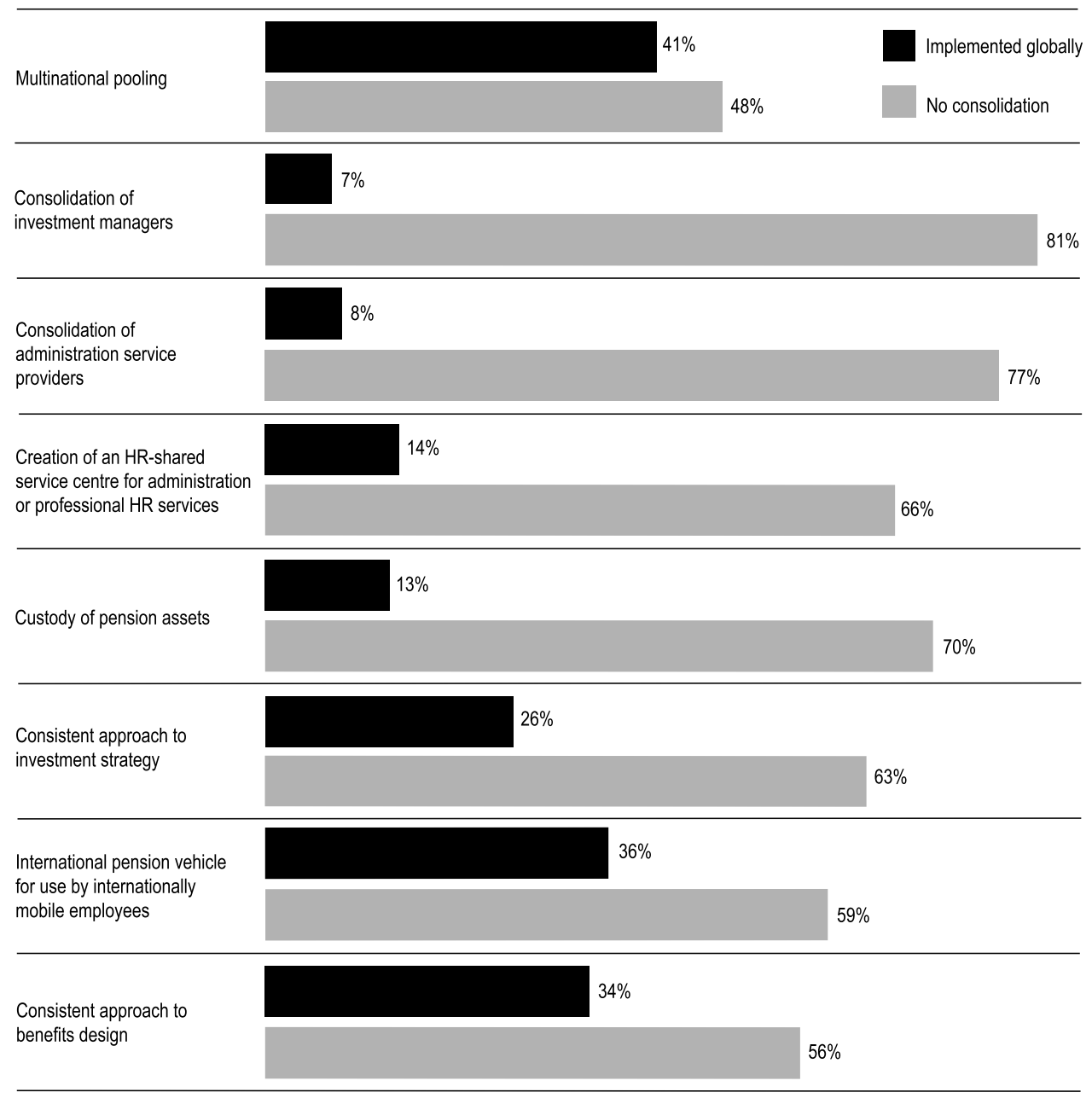

Figure 2: Prevalence of cost-saving tools and techniques

practices. With expectations for inflation exceeding 15 per cent-20 per cent, in general, expectations are for base pay adjustments equalling 70 per cent-80 per cent of the rise in the cost of living.

- Most companies do not plan to make special adjustments in executive compensation because of the peso's devaluation.

- A number of companies are looking at innovative ideas for bonus payments, including offshore payments, stock-linked mechanisms and local payments based on a fixed exchange rate. Any of these approaches may have legal and tax consequences that should be reviewed with advisers.

- Although most companies have taken steps to control the cost of health care plans, life insurance, perquisites and other benefits, price increases by providers are nonetheless creating real challenges.

- To retain managers and other key personnel, companies have developed specific individual training and development plans and reinforced peer coaching and mentoring programmes. In some cases, companies have encouraged employee 
involvement in projects outside the country and expanded participation in stock option programmes.

In response to the current crisis, employers in Argentina should consider:

- permanent monitoring of salary movements in the marketplace

- new financing vehicles for pension plans

- assessing the impact of cost increases in healthcare plans

- changing the design or calibration of annual incentive programmes

— adapting or replacing stock option programmes

- making sure they have effective employee communication programmes.

For further information please contact Zoltan Rosenfeld (rosenfz@towers.com), Buenos Aires, +54-11-4-131-2554.

\section{Australia}

\section{Licensing may be required for trustees of superannuation funds}

Trustees of superannuation (pension) funds will need to consider the implications of a new law imposing uniform licensing and disclosure requirements across the financial services industry. The changes represent an important reform for the industry in Australia and will replace existing superannuation, insurance, managed investments and deposit-taking disclosure regimes. Prudential supervision of superannuation funds is not affected by these reforms but is also under review.

The new requirements, introduced under the Financial Services Reform Act, came into effect on 11th March 2002, with a two-year transition period in most cases. They were developed with the fundamental goal of fostering greater consumer protection, and require any person who advises on or deals in financial products to be licensed.

Trustees of private company-sponsored superannuation funds are exempt from the licensing requirements, as long as they do not also provide 'financial product advice'. Though many funds will not benefit from the exemption, all trustees will be required to issue 'product disclosure statements' to members joining the fund and comply with other disclosure reforms

For further information please contact Warren Burford (burforw@towers.com), Sydney, +61-2-92295219.

\section{Europe}

\section{EU gives priority to pensions directive}

The European Union has prioritised the directive on prudential supervision of pension plans with the hope that it will be approved by the EU Council of Ministers in May. Since its approval by the European Parliament in July last year (see Headlines - September 2001), little progress has been made on the issue. The key areas of focus of the directive are:

- the adoption of the 'prudent person' principle for investments

- the introduction of baseline actuarial and funding standards

- the removal of barriers (apart from tax) to cross-border membership.

In adopting the 'prudent person' investment principle, the directive seeks to eliminate quantitative restrictions. However, there is still a lot of debate within the Council around allowing Member states to retain various kinds of restrictions. Funding issues have been debated without any firm conclusions, 
and cross-border membership requires a more in-depth analysis.

It therefore remains to be seen if any significant progress can be made in the coming months.

\section{European court ruling expected on cross-border pension case}

One of the main obstacles to cross-border membership is the discriminatory tax treatment applied to foreign plans by member states. Tax issues are not covered by the pensions directive, and in an effort to address this, the European Commission issued a communication in April last year stating that discriminatory tax treatment of cross-border pension provision was in breach of existing EU law (see Headlines June 2001).

The first case following this communication was heard at the European Court of Justice (ECJ) at the end of last year. It involves a German national, Rolf Danner, who moved to Finland and continued to pay contributions to his German pension plan. Finnish law does not allow a tax deduction on the contributions, and $\mathrm{Mr}$ Danner is claiming this is contrary to European law because he would be allowed the deduction if his contributions were made to a Finnish pension plan.

The advocate general's opinion is expected to be available shortly, with a possible court ruling by the end of this year. This could then pave the way for pan-European plans to become a reality.

The European commission had originally threatened to take member states with anti-tax discrimination laws to the ECJ. At present, however, it is adopting a more pragmatic approach by encouraging members to change their laws and relying on cases, such as the
Danner case, to bring matters to the ECJ.

Whatever the outcome, companies should ensure that they understand the tax and other implications of cross-border transfers and develop an appropriate policy.

\section{South Africa}

\section{New law on the use of pension fund surpluses goes into force}

Following several high-profile legal cases, the South African Parliament has approved comprehensive legislation on the use of surplus assets held in retirement funds. In addition, the legislation gives better protection to plan members, requiring minimum increases in pension payments and minimum benefits for members who withdraw from the fund.

The new law, the Pension Funds Second Amendments Act 2001, came into force on 7th December 2001 and requires all retirement funds with a surplus to submit an apportionment plan to the Registrar of Pension Funds.

The fund's board of management is required to identify those who have a stake in the fund and then apportion the surplus between some or all of them. In addition to current members and pensioners, the law recognises sponsoring employers as stakeholders, as well as former members who have withdrawn from the fund as far back as 1st January 1980.

The surplus must first be used to increase benefits previously paid to former members and to pensioners to meet the new minimum levels. Any balance can then be split on an equitable basis between the stakeholders. If surplus is apportioned to the employer, the employer is able to use it for contribution holidays or benefit 
improvements. A cash repayment is available only in very limited circumstances.

\section{Controversial feature}

A controversial feature of the new law is that any amount of surplus that has been 'improperly used' must be notionally added back into the calculation before the surplus is apportioned. This amount will then be deducted from any subsequent allocation of surplus to the employer or, if nothing is to be allocated to the employer, the amount becomes a debt owed by the employer to the fund. 'Improper uses' include:

- the value of any contribution holiday enjoyed by the employer

- the cost of benefit improvements for executives over and above the cost of benefits provided for other members

- the cost of pension enhancements granted to compensate selected members for the loss of any subsidy from the employer for post-retirement medical costs

- the cost of providing past service benefits to selected members or to members transferred into the fund in excess of any amount paid into the fund for the benefits.

While improper use of contribution holidays relates only to the period after the law came into force, improper use of surplus for benefit enhancements does not relate to any specific time period. This is of particular concern as employers may find themselves with a debt relating to the use of surplus to fund benefit enhancements over a number of years in the past.

Going forward, once the existing surplus has been apportioned, the law does not set any specific requirements for any future surplus.
For further information please contact Val Vardy (vardyv@towers.com), London, +44-(0)20-8895-3545.

\section{Spain}

\section{Government encourages company-sponsored pensions}

New measures designed to encourage qualified company-sponsored pension plans took effect on 1st January 2002. As well as the new contribution limits reported in Headlines - December 2001, important procedural changes are now in effect. These include:

- an increase in the number of company representatives in the plan control committee to 50 per cent so that employee representatives no longer have an absolute majority

- changes in the way in which amendments to the plan rules can be made

- changes to the decision-making process (at least 50 per cent of employee representatives' votes are now needed to approve investment strategy in defined contribution plans; and at least 50 per cent of company representatives' votes are needed to approve changes that can affect costs in defined benefit plans)

- changes in the definition as well as the requirements to access early retirement

- simplification of certain administration processes.

The Spanish government has also made changes in the social security system to encourage people to work beyond age 65 in order to ease the financial burden of the state pension system. The new measures, effective from 1st January 2002, include: 
- no Social Security contributions payable after the official state retirement age of 65 for employees who contributed to social security for at least 35 years

- the possibility of making the Social Security retirement pension compatible with work after normal retirement age

- mandatory Social Security contributions in case of 'pre-retirements' (collective severance programmes) for certain employees

— improvements to survivors' pensions.

There has been no change in the November 16th 2002 deadline for externally funding all company pension commitments through group insurance or qualified company-sponsored plans.

Employers should be addressing how they will implement the new measures and, at the same time, take the opportunity to consider their strategy for retirement going forward.

For further information please contact Sylvia Alvarino (alvaris@towers.com), Madrid, +34-91-590-3024.

\section{Sweden}

\section{Companies reviewing policy on employees' retirement plans}

Companies are reviewing the best use of employees' individual defined contribution arrangements. White-collar employees in Sweden typically receive benefits according to a plan defined in their collective agreement. This plan, known as the ITP plan, is a defined benefit multi-employer plan. Taken together, the ITP plan and Social Security provide a pension of roughly 65 per cent of final salary up to US $\$ 75,000$ a year (and 32.5 per cent between US $\$ 75,000$ and US $\$ 110,000$ ).

The collective agreement allows, with employer consent, employees earning in excess of about US $\$ 40,000$ to opt out of most of the ITP plan and instead establish an individual insured arrangement typically on a defined contribution (DC) basis.

Traditionally, opting out of the ITP plan occurs because brokers recommend a DC plan as a more beneficial approach for employees that can also be 'cost neutral' for the employer. Companies are now reconsidering whether this is an appropriate alternative, in the light of the following issues:

- Is the DC alternative really cost-neutral? It is not always easy to determine the cost of the ITP plan, and opting out can in some cases result in substantially higher cost.

- Would a company-specific DC plan provide a more appropriate benefit structure? Potential advantages can include better cost control for the company, a better appreciation of benefits by the employee, a benefit level that is seen as more equitable and more flexibility for the employee.

- Can the benefits be provided more cost effectively? The expense deductions for contributions can often be very large, particularly when considering the broker's commission. Companies have successfully reduced these deductions by negotiating directly with insurance companies.

Companies should consider if they are making the most of the flexibility that the collective agreement offers in the pension area. They should also ensure that they avoid the pitfalls that exist.

For further information please contact Mats Hagglund (mats.hagglund@hrs.se) Stockholm, +46-8-506-41722. 


\section{United Kingdom}

\section{Relaxation of minimum funding standard helps employers}

The government's announcement that the minimum funding requirements (MFR) will be abolished will now enable employers to:

- evaluate appropriate long-term strategies for their UK retirement plans without being constrained by short-term MFR issues

- work toward setting an appropriate funding policy, taking advantage of the flexibility that will now be available.

The MFR requirements were introduced in 1997 in an attempt to ensure that UK retirement plans maintained an acceptable level of funding, and so provide security for the benefits promised to plan members.

The rules have been continually criticised for producing short-term volatility in company contributions, with a distorting effect on investment decisions. The downturn in capital markets over the last two years has caused many plans to fall into an MFR deficit.

With the announcement that the MFR requirements will be completely abolished, probably starting in 2004, and replaced by a plan-specific funding approach, the government is currently working on the details to implement the proposals.

In the meantime, some MFR requirements have been relaxed effective from March 2002, as follows:

- An extension to the period to remove any MFR funding deficit. The period has been extended from one year to three years to bring the funding level back to 90 per cent and from three years to ten years to reach 100 per cent funding.

- A change to the financial assumptions to calculate benefit liabilities, reducing the funding liability for non-pensioner members.

- Removal of the annual check on the funding level for plans that were 100 per cent funded on the MFR basis at the last triennial valuation.

Employers should now consider the impact these changes will have on their benefit strategy for the future.

For more information please contact Michael Hammer (hammerm@towers.com), London, +44-(0)20-8895-3586 or Charles Young (younc@towers.com), London, +44-(0)20-8895-3410.

\section{United States}

\section{Annual incentive plans use many common features, new study shows}

Company annual incentive or bonus plans, which play a key role in efforts of most Fortune 500 companies to drive executive performance, increasingly share many of the same basic features, according to the '2001 Towers Perrin Annual Incentive Plan Design' Survey of 237 large US-based companies.

Among the survey's key findings were the following points:

- 62 per cent of respondents reported that they currently use three or more measures to determine bonus payouts. Earnings per share is the most commonly used performance measure (34 per cent), followed by revenue measures (25 per cent), measures of net income or profit (22 per cent), and earnings before interest and taxes or EBIT (14 per cent).

- More than half the companies adopt 
corporate non-financial measures or individual performance measures to determine awards. The most frequently used corporate non-financial measures include customer satisfaction, employee satisfaction, quality and new product development.

- About 66 per cent of the respondents use at least two different methods to determine performance expectations, or standards, for their main performance measure. While budgeted performance is the most commonly used standard (60 per cent), increasing numbers of companies also consider business conditions (49 per cent), year-to-year growth (48 per cent) and/or investor expectations $(27$ per cent).

— Nearly 70 per cent of respondents said that they employ a single criterion to determine plan eligibility, with position in the company cited most frequently (44 per cent), followed by salary grade (38 per cent).

Most companies review their incentive plan designs fairly regularly and modify them as needed in order to ensure effectiveness. Nearly 60 per cent have reviewed their plan at least three times in the last three years, and 55 per cent of them have made significant modifications at least once. Companies are also placing more emphasis on the process of setting performance expectations and are considering a variety of factors to determine performance standards.

At the same time, however, the move toward widespread similarity among bonus plans at a broad cross-section of companies raises the question of whether these companies, each with arguably different executive compensation needs, are getting maximum value and competitive advantage from an essential pay component.

Copies of the survey are available in the USA by calling (800) 525-6741, or outside the United States by contacting the nearest Towers Perrin office.

For further information please contact Annalisa Barrett (barreta@towers.com), Detroit, +1-313-945-6468 or Doug Friske(frisked@towers.com), Chicago, +1-312-609-9137.

(C) Towers Perrin 